\title{
Use of medicines by older people in a large British national survey, and their relation to vitamin status indices
}

\author{
Christopher J Bates ${ }^{1, *}$, Catherine M Walmsley ${ }^{1}$, Ann Prentice ${ }^{1}$ and Steven Finch ${ }^{2}$ \\ ${ }^{1}$ MRC Human Nutrition Research, Downhams Lane, Milton Road, Cambridge CB4 IX, UK: ${ }^{2}$ Social and \\ Community Planning Research, 35 Northampton Square, London ECIV OAX, UK
}

Submitted 5 June 1998: Accepted 3 September 1998

\begin{abstract}
Objective: To describe the extent of use of medicines by older people living in Britain, and to explore relationships with vitamin status indices.

Design: The National Diet and Nutrition Survey of people aged 65 years and over collected data from a British sample during 1994-95. The present study has made novel use of it, to relate medicine use with biochemical indices of vitamin status. Setting: Eighty postcode areas, selected randomly from mainland Britain. Subjects: 1506 people, 65 years and over gave information about use of medication, and a 4-day weighed food record. Three-quarters gave blood for status indices. Results: $78 \%$ of those living in the community and $93 \%$ of those in institutions were using medication. Certain vitamin status indices: plasma retinol, erythrocyte folate and riboflavin, paradoxically suggested better status in users than in non-users of antihypertensive, gastrointestinal, central nervous system, corticosteroid or diabetic drugs. There was evidence of a link with renal insufficiency, especially for plasma retinol, but neither this nor increased nutrient intake, acute phase effects or haemoconcentration could explain the paradoxical associations.

Conclusions: Caution is needed in interpreting certain vitamin status indices, especially in older people who are extensively using medicines. New vitamin indices are needed, to avoid confounding interferences.
\end{abstract}

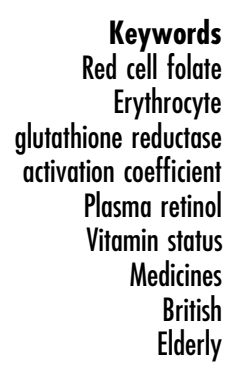

Biochemical indices of nutritional status, especially for micronutrients, can provide a valuable source of information about nutrient adequacy, either alone or in conjunction with estimates of nutrient intakes and clinical or physiological evidence of status ${ }^{1,2}$. Those indices which are based on measurements of the concentration of a specific nutrient in an accessible body fluid such as urine, serum, plasma or red cells may, for some nutrients, accurately reflect recent or medium-term integrated nutrient intakes. A confounding influence, however, may be the effect of medicines, and of the disease processes which they are used to control $^{3-9}$. Because of the enormous numbers and varieties of medicines which are in use, and the complexity of their interactions with physiological processes, the description and investigation of such interactions has proved a very demanding task. In studying the nutritional status and nutrient requirements of vulnerable groups of people, especially the sick and elderly, this is an important subject for investigation, because of the risk of misinterpretation of analytical data ${ }^{2,3}$.

Drug interference phenomena can be of several kinds. One is the direct interference by the drug or its metabolites, present in the analytical sample, in the performance of an analytical assay ${ }^{9}$. More common, and more complex, however, are metabolic drug interferences, whereby key physiological processes, such as the absorption, excretion, turnover rate or tissue distribution of specific nutrients, may be affected $^{5-8}$. In theory, the medicine may either affect overall (body) status of the nutrient, or it may alter nutrient distribution so that one or more status indices are affected, whereas overall status remains unchanged. Alterations in status in medicine users could, alternatively, be caused by the medical condition being treated, and not by the medicines per se.

The purpose of the present study was firstly to summarize the extent of usage of medicines by a representative sample of older British people, and secondly to explore some apparently paradoxical relationships between vitamin status indices and the use of medicines. The study was linked to the National Diet and Nutrition Survey of people aged 65 years and over, carried out during $1994-95^{10}$.

\section{Subjects and methods}

The design and execution of the National Diet and Nutrition Survey of people aged 65 years or over 
in mainland Britain has been described in detail elsewhere ${ }^{10}$; therefore only the main features are summarized here. Ethical approval for the survey was given by the Local Research Ethics Committees for each of the postcode sectors involved, and by the MRC Dunn Nutrition Unit's ethics committee. Potential participants were randomly selected, during 1994-95, from 80 randomly chosen postcode sectors, by Social and Community Planning Research (SCPR), on behalf of the British government (Department of Health and Ministry of Agriculture, Fisheries and Food). Within each sector, private households (the 'non-institution' sample) and long-stay institutions such as nursing homes (the 'institution' sample), were represented. Predetermined numbers, for statistical adequacy, were recruited from each gender and from each of three age groups: $65-74,75-84$ and $85+$ years. This required some deliberate oversampling of male subjects, and the older groups. About two-thirds of the sample approached provided a 4-day weighed dietary record and about one half provided a blood sample.

A structured interview by a trained fieldworker provided information on health and lifestyle factors, and was followed by a supervised 4-day weighed dietary record; including details of all dietary supplements used, in the subjects' own home. An early morning blood sample, usually fasting, was obtained in the home by a trained nurse, and was immediately subdivided into subsamples for haematology and for haematinic nutrients (including serum vitamin $\mathrm{B}_{12}$ ) performed at Addenbrooke's Haematology Laboratory, Cambridge, UK. The remaining biochemical index measurements were performed at the MRC Dunn Nutrition Unit (now MRC Human Nutrition Research), Cambridge, UK, after initial subdivision, stabilization and storage (at $-40^{\circ} \mathrm{C}$ or below) at an intermediate hospital laboratory, to which the samples were taken usually within $4 \mathrm{~h}$, in a cool box.

Detailed information about the use of medicines was obtained by the nurse when visiting the subjects' home (or other place of domicile, e.g. institution). The brand name, strength, amount and frequency of use, and product licence number were recorded for each drug, by reference to the information on the bottle, packet, etc. This information was subsequently coded, using a Department of Health Medicines Coding Frame, into 13 major categories (cardiovascular; gastrointestinal; respiratory; central nervous system; infections; endocrine; obstetrics and gynaecology; cytotoxic; nutrition and blood; musculoskeletal; eye, ear, nose and throat; skin; and 'other' including aspirin). The only category which contained any vitamins in the formulation was that described as 'nutrition and blood', which frequently included folate and/or vitamin $\mathrm{B}_{12}$. The major categories were then further subdivided into 39 subcategories. A score for each subject, category and subcategory was obtained, scoring 1 for each type of drug that was used regularly. Each subject would thus score 0 (none used) or 1 (one drug used) or an integer greater than one, if more than one drug in that category was being used regularly, at the time of the survey. Each participant received one series of visits, over approximately a 2 -week period, and the entire survey fieldwork was carried out in four waves, corresponding to the four seasons, between October 1994 and September 1995, thereby spanning a single calendar year.

The vitamin status index and other biochemical assay procedures are described in detail elsewhere ${ }^{10}$. Briefly, vitamins $\mathrm{A}, \mathrm{E}$ and the carotenoids were measured by high pressure liquid chromatography ${ }^{11}$; the red cell enzyme indices for thiamin and riboflavin status were measured on a Roche Cobas Bio centrifugal analyser ${ }^{12,13}$; serum vitamin $B_{12}$ was measured by an inhouse competitive binding assay based on intrinsic factor; serum folate was measured by a microbiological assay; red cell folate was measured by a kit assay (BioRad Quantaphase II, BioRad, Hemel Hempstead, Herts, UK). Plasma urea and creatinine were measured on a Roche Cobas Bio centrifugal analyser with Roche kit reagents ${ }^{10}$; plasma $\alpha_{1}$-antichymotrypsin were measured on the same analyser, with Dako Ltd (High Wycombe, Bucks, UK) reagents ${ }^{10}$. The choice of $\alpha_{1}$-antichymotrypsin as an acute phase marker has been validated ${ }^{14}$.

Diet records were coded at SCPR and were used to calculate individual daily nutrient intakes from tables, using a specially developed nutrient databank, based on standard food composition tables. Estimates of additional vitamin intakes from non-prescribed vitamin supplements (tablets, syrups, etc.) were calculated; vitamin-containing supplements were being used at the time of the interview by $20 \%$ of the participants not living in institutions and by $14 \%$ of those in institutions. 1506 subjects provided an adequate 4-day food intake record, of whom 1169 also provided a blood sample for the biochemical status index measurements.

Data reduction was performed by Microsoft Excel and Data Description Inc., DataDesk personal computer packages, using multiple regression models (with or without log transformation as appropriate) and by the DataDesk General Linear Model for categorized data (Fig. 1). Two tail hypothesis tests were used throughout, and since a large number of comparisons were made, $P<0.01$ was chosen as the cut-off for significant differences.

\section{Results}

Table 1 gives details of the number of different medicines which were regularly used by the survey 


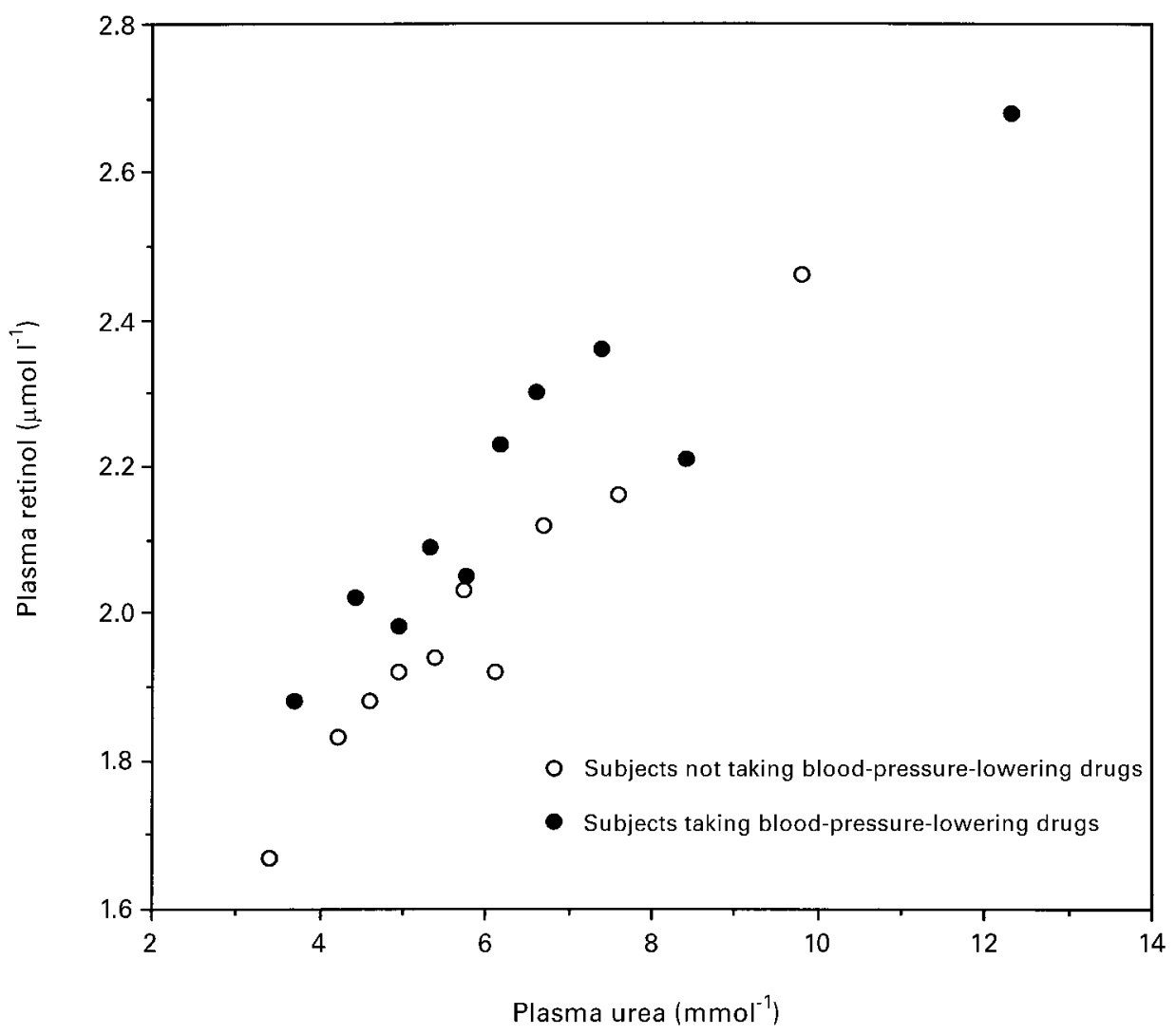

Fig. 1 Corrected plasma retinol concentration, by category of increasing plasma urea concentration, in subjects taking, and in subjects not taking, blood pressure-lowering drugs. For each group of subjects, the plasma urea concentrations were subdivided into ten equal segments of ascending concentration, and were entered into a general linear model (DataDesk) as the dependent variable, with either the plasma retinol concentration or the erythrocyte glutathione reductase activation coefficient as the primary independent variables, and age, gender and domicile as the secondary independent variables. For the subjects who were not taking blood pressure-lowering (antihypertensive) drugs, there was an average of 64 results per cell; for those taking blood pressure-lowering drugs (categories a to $g$ of 'cardiovascular' drugs in Table 2) there was an average of 46 results per cell. The overall significance of the relationship between plasma urea and plasma retinol concentration, corrected for age, gender and domicile, was $t=+13.5 ; P<0.0001$

participants. Overall, only $18 \%$ of the participants were not using any medicines, with slightly greater usage by females than males, in the free-living category. People living in institutions each used about twice as many medicines as each free-living participant, and this pattern was consistent, regardless of age and gender.

Table 2 gives a breakdown of the use of different categories of medicines. The three largest categories of medicines use were those for cardiovascular, gastrointestinal and central nervous system (CNS) diseases. The latter two categories were especially extensively used by the institutionalized subjects. Of the ten subcategories of cardiovascular drugs being used, the first seven subcategories in Table 2 are frequently described as 'antihypertensive' or 'blood pressure-lowering' drugs, whereas the other three categories are used to combat other effects of cardiovascular diseases.

Table 3 provides an analysis of the differences between users and non-users of six main categories and three subcategories of medicines, with respect to the blood vitamin status index values, in the subset of participants who provided a blood sample for biochemical analysis. Log-transformation was used where appropriate; corrections for age, gender and domicile (free-living or institution) and the corresponding nutrient intake estimate were included. Medicine categories for which there were no significant differences for these status indices were omitted from this table. For most of the comparisons shown in Table 3 , the result was similar if the index of medicine use was simply 'yes or no' for the category of interest, instead of 'number of medicines used' in the category. An exception to this was encountered for CNS drugs, however, where two of the apparent interactionswith erythrocyte glutathione reductase activation coefficient (riboflavin status) (EGRAC) and erythrocyte transketolase activation coefficient (thiamin status) (ETKAC)-became non-significant if the simple 'yes or no' distinction were used. The relation between number of CNS drugs used and the mean value of ETKAC was particularly strong for the institution group, as depicted in Table 4 . The direct positive relationship with number of CNS drugs used was weak and 
Table 1 Total medicine use by a representative sample of British people aged 65 and over

\begin{tabular}{|c|c|c|c|c|c|c|c|c|}
\hline \multirow{3}{*}{$\begin{array}{l}\text { Number of } \\
\text { medicines } \\
\text { used regularly }\end{array}$} & \multicolumn{8}{|c|}{ Category } \\
\hline & \multicolumn{2}{|c|}{$\begin{array}{c}\text { All } \\
\text { subjects }\end{array}$} & \multicolumn{2}{|c|}{$\begin{array}{l}\text { Non-institution } \\
\text { males }\end{array}$} & \multicolumn{2}{|c|}{$\begin{array}{l}\text { Non-institution } \\
\text { females }\end{array}$} & \multicolumn{2}{|c|}{$\begin{array}{l}\text { Living in } \\
\text { institutions, } \\
\text { both sexes }\end{array}$} \\
\hline & $n$ & $\%$ & $n$ & $\%$ & $n$ & $\%$ & $n$ & $\%$ \\
\hline None & 273 & 18 & 138 & 24 & 108 & 19 & 27 & 7 \\
\hline 1 & 260 & 17 & 127 & 22 & 108 & 19 & 23 & 6 \\
\hline 2 & 287 & 19 & 114 & 20 & 122 & 22 & 50 & 14 \\
\hline 3 & 215 & 14 & 63 & 11 & 94 & 17 & 50 & 13 \\
\hline 4 & 162 & 11 & 51 & 9 & 49 & 9 & 61 & 16 \\
\hline $5-10$ & 293 & 20 & 80 & 14 & 74 & 13 & 15 & 41 \\
\hline$>10$ & 16 & 1 & 2 & $<1$ & 5 & 1 & 9 & 3 \\
\hline Total & 1506 & 100 & 575 & 100 & 560 & 100 & 371 & 100 \\
\hline
\end{tabular}

Analyses were confined to that subset of the total sample who provided a food diary record, of whom $24 \%$ lived in an institution and $78 \%$ (overall) provided a blood sample for biochemical status assays. The numbers in each category and the percentage distributions in the table have been corrected by weighting factors, which represented the disproportionate sampling of the population, being necessary to obtain sufficient numbers, e.g. of older males, for satisfactory statistical analysis of all survey subgroups. On average, each non-institution subject was using 2.4 different medicines and each subject in an institution was using 4.3 different medicines. This pattern was relatively little affected by gender or age.

Table 2 Medicines use by category, by a representative sample of British people aged 65 and over

\begin{tabular}{|c|c|c|c|c|c|c|}
\hline \multirow[b]{3}{*}{ Medicines category } & \multicolumn{6}{|c|}{ Category } \\
\hline & \multicolumn{2}{|c|}{$\begin{array}{c}\text { All } \\
\text { subjects }\end{array}$} & \multicolumn{2}{|c|}{$\begin{array}{l}\text { Non-institution, } \\
\text { both sexes }\end{array}$} & \multicolumn{2}{|c|}{$\begin{array}{l}\text { Living in } \\
\text { institutions, } \\
\text { both sexes }\end{array}$} \\
\hline & $n$ & $\%$ & $n$ & $\%$ & $n$ & $\%$ \\
\hline Base & 1506 & 100 & 1135 & 100 & 371 & 100 \\
\hline $\begin{array}{l}\text { Cardiovascular: total } \\
\text { (I) Antihypertensive drugs } \\
\text { (a) diuretics } \\
\text { (b) } \beta \text {-blockers } \\
\text { (c) combined (a) and (b) } \\
\text { (d) ACE inhibitors } \\
\text { (e) vasodilators; centrally acting drugs } \\
\text { (f) sympatholytics } \\
\text { (g) calcium blockers }\end{array}$ & $\begin{array}{r}710 \\
410 \\
129 \\
42 \\
89 \\
14 \\
13 \\
150\end{array}$ & $\begin{array}{r}47.1 \\
\\
27.2 \\
8.6 \\
2.8 \\
5.9 \\
0.9 \\
0.9 \\
10.0\end{array}$ & $\begin{array}{r}515 \\
263 \\
117 \\
36 \\
68 \\
10 \\
10 \\
116\end{array}$ & $\begin{array}{r}45.4 \\
\\
23.2 \\
10.3 \\
3.2 \\
6.0 \\
0.9 \\
0.9 \\
10.1\end{array}$ & $\begin{array}{r}186 \\
143 \\
10 \\
5 \\
20 \\
4 \\
2 \\
31\end{array}$ & $\begin{array}{r}51.1 \\
38.5 \\
2.7 \\
1.3 \\
5.4 \\
1.1 \\
0.6 \\
8.4\end{array}$ \\
\hline $\begin{array}{l}\text { (II) Other cardiovascular } \\
\text { (h) anticoagulants } \\
\text { (i) lipid-lowering drugs } \\
\text { (j) other }\end{array}$ & $\begin{array}{r}16 \\
16 \\
248\end{array}$ & $\begin{array}{r}1.1 \\
1.1 \\
16.5\end{array}$ & $\begin{array}{r}14 \\
15 \\
167\end{array}$ & $\begin{array}{r}1.2 \\
1.3 \\
14.7\end{array}$ & $\begin{array}{r}2 \\
0 \\
79\end{array}$ & $\begin{array}{c}0.6 \\
0 \\
21.3\end{array}$ \\
\hline Gastrointestinal & 393 & 26.1 & 200 & 17.6 & 190 & 51.2 \\
\hline Respiratory & 157 & 10.4 & 115 & 10.1 & 40 & 10.8 \\
\hline CNS & 594 & 39.4 & 343 & 30.2 & 245 & 66.0 \\
\hline Anti-infection & 81 & 5.4 & 50 & 4.4 & 29 & 7.8 \\
\hline Endocrine & 236 & 15.7 & 146 & 12.9 & 60 & 16.2 \\
\hline Cytotoxic & 11 & 7.3 & 20 & 1.7 & 10 & 2.7 \\
\hline Nutrition/blood & 123 & 8.2 & 62 & 5.5 & 59 & 15.9 \\
\hline Musculoskeletal & 40 & 2.7 & 33 & 2.9 & 6 & 1.6 \\
\hline Eye, ear, nose, throat & 101 & 6.7 & 68 & 6.0 & 32 & 8.6 \\
\hline Skin & 124 & 8.2 & 86 & 7.6 & 37 & 10.0 \\
\hline Other incl. aspirin & 355 & 23.6 & 240 & 21.1 & 111 & 29.9 \\
\hline
\end{tabular}

Analyses were confined to that subset of the total sample who provided a food diary record, of whom $78 \%$ (overall) provided a blood sample for biochemical status assays. The numbers and percentages in each category in the table have been corrected by a weighting factor to correct for the disproportionate sampling, as in Table 1. Some of the subjects were taking more than one medicine in a medicine category, and a large proportion were taking several medicines in each of several different categories (see Table 1). 
Table 3 Differences* between users and non-users of medicines, for selected nutrient status indices

\begin{tabular}{|c|c|c|c|c|c|c|c|}
\hline \multirow{2}{*}{$\begin{array}{l}\text { Medicine } \\
\text { category } \\
\text { index }\end{array}$} & \multicolumn{6}{|c|}{ Nutrient status indices $\dagger$} & \multirow[b]{2}{*}{$\begin{array}{c}\text { Plasma } \\
\text { ascorbate }\end{array}$} \\
\hline & $\begin{array}{c}\text { Plasma } \\
\text { retinol }\end{array}$ & $\begin{array}{l}\text { Plasma } \\
\text { lutein } \ddagger\end{array}$ & ETKAC $\ddagger$ & EGRAC $\ddagger$ & $\begin{array}{c}\text { Serum } \\
\text { vitamin } B_{12}\end{array}$ & $\begin{array}{l}\text { Red cell } \\
\text { folate }\end{array}$ & \\
\hline All antihypertensives & $<0.0001(+) \S$ & $\mathrm{N}$ & $\mathrm{N}$ & $0.002(-) \S$ & $\mathrm{N}$ & $<0.0001(+)$ & $\mathrm{N}$ \\
\hline (a) diuretics & $<0.0001(+) \S$ & $\mathrm{N}$ & $\mathrm{N}$ & $0.009(-) \S$ & $\mathrm{N}$ & $<0.0001(+)$ & $\mathrm{N}$ \\
\hline (b) combined diuretics and $\beta$-blockers & $0.0001(+)$ & $\mathrm{N}$ & $\mathrm{N}$ & $\mathrm{N}$ & $\mathrm{N}$ & $0.01(+)$ & $\mathrm{N}$ \\
\hline (c) calcium blockers & $\mathrm{N}$ & $\mathrm{N}$ & $\mathrm{N}$ & $0.02(-)$ & $\mathrm{N}$ & $\mathrm{N}$ & $\mathrm{N}$ \\
\hline Gastrointestinal & $0.006(+)$ & $\mathrm{N}$ & $\mathrm{N}$ & $\mathrm{N}$ & $\mathrm{N}$ & $\mathrm{N}$ & $\mathrm{N}$ \\
\hline CNS & $0.009(+) \S$ & $0.004(-)$ & $0.001(+)$ & $0.01(+)$ & $\mathrm{N}$ & $\mathrm{N}$ & $\mathrm{N}$ \\
\hline Nutrition and blood & $\mathrm{N}$ & $\mathrm{N}$ & $\mathrm{N}$ & $\mathrm{N}$ & $<0.0001(+)$ & $<0.0001(+)$ & $\mathrm{N}$ \\
\hline Corticosteroids & $0.002(+) \S$ & $\mathrm{N}$ & $\mathrm{N}$ & $\mathrm{N}$ & $\mathrm{N}$ & $\mathrm{N}$ & $\mathrm{N}$ \\
\hline Diabetic & $\mathrm{N}$ & $\mathrm{N}$ & $\mathrm{N}$ & $0.004(-)$ & $\mathrm{N}$ & $\mathrm{N}$ & $\mathrm{N}$ \\
\hline
\end{tabular}

* Calculated by multiple regression, with the vitamin status index as the dependent variable and the number of drugs used (nil or positive integer) in the medicines category, as the independent variable of primary interest, together with age, gender and domicile (community or institution) and the corresponding nutrient intake estimate as the secondary independent variables. Results are expressed as the probabilities $(P)$ for rejection of the null hypothesis for an association with drugs use, with the direction (+ meaning a greater value for the medicine users; - meaning a greater value for non-users), in parentheses. For clarity, all differences which did not achieve significance at $P \leq 0.01$ are designated N (not significant), except for the relation between calcium blockers and EGRAC, whose $P$ value of 0.02 was potentially relevant to the relation between antihypertensive drugs and EGRAC. The other groups of drugs listed in Table 2 did not exhibit differences for any of these vitamin status indices, significant at $P \leq 0.01$.

$\dagger$ Including the plasma carotenoid, lutein, whose concentration in plasma was strongly correlated with dietary carotenoid intakes $(P<0.0001)$.

$\ddagger$ Log-transformed.

$\S$ Probability (rejection of null hypothesis) was no longer significant after introduction of plasma urea into the model. For all other significant relationships in Table 3, the introduction of plasma urea had essentially no effect.

ETKAC, erythrocyte transketolase activation coefficient (thiamin status); EGRAC, erythrocyte glutathione reductase activation coefficient (riboflavin status).

non-significant for the basal activity of transketolase; it was significant $(P=0.02)$ for the stimulated activity and it was highly significant $(P=0.0002)$ for the activation coefficient. In this case, it was the users of several medicines in the same category which seemed to dominate the interactions, moreover the progressive increase in ETKAC was not fully explained by decreasing thiamin intakes (not shown).

Attenuation, by the addition of plasma urea was explored to test for possible effects of impaired renal function. Plasma urea markedly reduced the significance of the difference for plasma retinol, for users of antihypertensive (diuretic) and of CNS drugs, and for EGRAC for users of diuretic drugs (Table 3). Figure 1 shows the relation between plasma retinol and plasma urea, in both users and non-users of antihypertensive drugs. There is clearly a strong relation with urea in both categories of subjects, but the drug-users had higher retinol concentrations at each concentration of urea, than non-users. Plasma $\alpha_{1}$-antichymotrypsin was used to test for acute phase effects, associated with infections, inflammation, etc., which are known to affect some vitamin status indices, independently of vitamin intakes or overall body status. No attenuation by this marker was observed, for any of the relationships shown in Table 3 (not shown).

Comparisons of nutrient intakes between medicine users and non-users, focusing on those nutrients and medicines for which significant status differences were found (see Table 3) showed that in most cases, no significant differences in intakes were detectable (not shown). The only exceptions to this were that people taking CNS medication had lower intakes of carotenoids and of thiamin, and that people taking drugs in the 'nutrition and blood' category had higher intakes of folic acid and vitamin $\mathrm{B}_{12}$, presumably because these were included as part of the medication.

The possibility that elderly people (especially those who take drugs which affect water balance, such as diuretics), or those who drink inappropriately for other reasons may experience haemoconcentration or haemodilution, was tested by examining their blood haemoglobin concentrations, haematocrits and plasma albumin levels. Of the drug categories studied, the majority exhibited either no correlation or an inverse correlation, with haemoglobin and haematocrit (not shown); therefore there was no evidence for any association between drugs use and haemoconcentration, which in turn suggests that the high plasma retinol cannot be explained by haemoconcentration effects. An inverse relationship with both plasma albumin and retinol was detected in respiratory and endocrine drugusers $(P<0.001$, not shown). This might be due to haemodilution or, more likely, to an acute phase reaction, which is known to reduce albumin levels ${ }^{4}$.

\section{Discussion}

Many older people are regular users of a wide range of medicines, often for chronic diseases associated with the ageing process. The data collected in the course of the National Diet and Nutrition Survey of older people living in Britain indicates the high frequency of use of such medication, the numbers of different medicines that are used by individuals, and the relative frequency of use of medicines in different categories (see Tables 1 and 2). It is of potential concern that these medications may affect normal metabolism, including nutritional status indices, in a multitude of ways, many of which are poorly understood. Previous studies of interactions 




between drugs and nutrition ${ }^{5-8}$ have shown that certain categories of drugs may interfere with nutrient utilization, resulting in actual deficiency. However, this represents only one facet of an extensive range of interactions, including subtle redistribution of nutrients between the body compartments. It is often difficult to distinguish between the effects of the disease processes per se and those of the drugs used to treat them, in cross-sectional population studies. Those studies which aim to characterize the nutritional status of older people, and to relate dietary nutrient intakes with status indices, may encounter problems of interpretation resulting from the effects of disease on nutritional indices, and the effects of medicines on these indices.

In the present study, the questions asked were, are there any significant differences in vitamin status between drugs-users and non-users, and if so, can they be explained by dietary differences, or are the reasons likely to be non-diet related? Possible explanations for the latter could be:

1 Underlying illnesses that may alter vitamin status even before the start of medication. An acute phase reaction, or haemoconcentration or haemodilution effects caused by water imbalance, might be responsible.

2 A metabolic effect of medication that may alter vitamin status, e.g. by altering the availability, turnover, excretion or tissue distribution of vitamins or their carrier proteins. A special case might be a redistribution between pools, so that a compartment such as blood plasma or a particular biochemical test is affected, even though overall status is not.

Of the status indices listed in Table 3, all except ETKAC and EGRAC are expected to increase with an improvement in status, and to decrease with a worsening of status. By contrast, ETKAC and EGRAC, being an estimate of degree of unsaturation of erythrocyte enzymes with vitamin-derived cofactors, increase with worsening status. Some of the significant differences between medicine users and non-users in Table 3 paradoxically imply better status in the group receiving medication, namely: plasma retinol for six categories of medicines; EGRAC for four categories; red cell folate for four categories, and serum vitamin $\mathrm{B}_{12}$ for 'nutrition and blood' medication. The remaining significant differences in Table 3 imply worse vitamin status in the groups receiving the medication. In this study, there were no significant $(P<0.01)$ associations between use of drugs and vitamin $C$ status (plasma ascorbic acid concentration), although an inverse association at $P=0.02$ with drugs used for 'nutrition and blood' treatments was observed, suggesting that patients in this category had generally poor micronutrient status. 
Medicines used to correct haematological evidence of poor nutrition may include the haematinic nutrients: iron, folic acid and vitamin $\mathrm{B}_{12}$. Therapeutic doses of folic acid and/or vitamin $B_{12}$ were indeed associated with increased serum vitamin $B_{12}$ and red cell folate concentrations (Table 3). The CNS category of drugs included opiates (but not aspirin), non-steroidal antiinflammatory drugs, antidepressants, anti-insomnia drugs, and drugs to treat affective disorders, nausea and vomiting, migraine, epilepsy, parkinsonism and substance-dependence. Intakes of thiamin were, on average, lower in people using CNS drugs than in those not using them and this group also had poor thiamin status, as indicated by raised values of ETKAC. In the institution group, at least, low thiamin intakes failed to explain the raised ETKAC values, so other risk factors must also exist in this group of subjects. Thiamin supplements may therefore be required by older people who use several drugs in the CNS category.

The possibility that medicines might affect the carrier proteins for micronutrients was considered but appears unlikely. If medicines compete with nutrients for carrier proteins, then plasma nutrient levels should decline, but no decline was observed, and indeed the concentration of retinol increased. If medicines could induce and thus increase the level of specific carrier proteins, there might be an enhancement of plasma vitamin concentrations, but no such increase in protein was observed, at least for plasma albumin. A specific enhancement of retinolbinding protein synthesis cannot be ruled out, but this would not explain the observed changes in red cell folate or EGRAC, which are intracellular indices. Previous studies have, however, shown that riboflavin status as measured by EGRAC may improve, paradoxically, during inanition consequent upon lack of food $^{15}$ or during disturbances of redox status consequent upon glucose-6-phosphate dehydrogenase deficiency ${ }^{16}$. It seems possible that analogous mechanisms may come into play in certain categories of drug-users.

One possible explanation of increased plasma retinol concentrations could be impaired renal function ${ }^{17-22}$. Plasma urea (a marker of impaired renal function) was therefore introduced into the regression model. Attenuation of the relationships between medicine use and vitamin status was seen principally for antihypertensive drugs, affecting plasma retinol and EGRAC and for CNS drugs, affecting plasma retinol only. Otherwise, there were no major attenuations by either plasma urea or plasma creatinine, nor by the acute phase marker: plasma $\alpha_{1}$-antichymotrypsin. In contrast to other studies ${ }^{17-22}$, plasma urea appeared to be a more effective indicator of renal insufficiency than plasma creatinine. Users of antihypertensive medicines had consistently higher plasma retinol concentrations at each plasma urea concentration, than non-users of these medicines.
Some previous studies have reported relationships similar to those of the present study, between drugs use and vitamin status indices ${ }^{23-27}$. A study by Herbeth $e t$ $a l .{ }^{26}$ found direct relationships between plasma retinol concentrations and the use of medicines by elderly European subjects, but the relation with renal function was not explored.

The principal conclusions from the present study are that the use of medication is widespread among older people in Britain and that the interpretation of several commonly used biochemical indices of vitamin status may be dominated by non-nutritional effects, in elderly people with chronic illnesses and medications. Further studies are needed to explain these effects and determine which of them may be the result, either of specific medical conditions, or of metabolic effects of certain types of medication. If possible, it would be very useful to devise new status indices, to help overcome the ambiguities of interpretation which arise when these confounding influences occur.

\section{Acknowledgements}

The National Diet and Nutrition Survey of people aged 65 years and over was funded jointly by the Ministry of Agriculture, Fisheries and Food and the Department of Health, and conducted by Social and Community Planning Research, in conjunction with the Medical Research Council's Dunn Nutrition Unit. CMW was supported by a grant from the Ministry of Agriculture, Fisheries and Food. Measurements of vitamin $\mathrm{B}_{12}$ were carried out by Mr B Tolliday's team at Addenbrooke's Hospital Department of Haematology. We are indebted to Dr TJ Cole for statistical advice.

\section{References}

1 Bates CJ. Vitamin analysis. Ann. Clin. Biochem. 1997; 34: 127.

2 Bates CJ, Thurnham DI, Bingham SA, Margetts BM, Nelson M. Biochemical markers of nutrient intake. In: Margetts BM, Nelson M, eds. Design Concepts in Nutritional Epidemiology, second edition. Oxford: Oxford University Press, 1997: $170-240$.

3 Thurnham DI. Micronutrients: how important in old age? Eur. J. Clin. Nutr. 1992; 46 (suppl. 3): S29-S37.

4 Thurnham DI. Impact of disease on markers of micronutrient status. Proc. Nutr. Soc. 1997; 56: 521-31.

5 Smith $\mathrm{CH}$, Bidlack WR. Dietary concerns associated with the use of medications. J. Am. Diet. Ass. 1984; 84: 901-14.

6 Chen LH, Liu S, Cook Newell ME, Barnes K. Survey of drug use by the elderly and possible impact of drugs on nutritional status. Drug-Nutrient Interactions 1985; 3 :73-86.

7 Roe DA. Diet and Drug Interactions. New York: Van Nostrand Reinhold, 1988.

8 Basu TK. Drug-Nutrient Interactions. London: Croom Helm, 1988.

9 Tietz NW, Finley PR, Pruden EL. Clinical Guide to Laboratory Tests, second edition. Philadelphia: Saunders, 1990. 
10 Finch S, Doyle W, Lowe C, Bates CJ, Prentice A, Smithers G, Clarke PC. National Diet and Nutrition Survey: people aged 65 years and over, vol. 1: Report of the Diet and Nutrition Survey. London: SO, 1998.

11 Thurnham DI, Smith E, Flora PS. Concurrent liquidchromatographic assay of retinol, $\alpha$-tocopherol, $\beta$-carotene, $\alpha$-carotene, lycopene and $\beta$-cryptoxanthin in plasma, with tocopherol as internal standard. Clin. Chem. 1988; 34: 377-81.

12 Vuilleumier JP, Keller HE, Keck E. Clinical chemical methods for routine assessment of the vitamin status of populations. Part III. The apoenzyme stimulation tests for vitamins $\mathrm{B}_{1}, \mathrm{~B}_{2}$ and $\mathrm{B}_{6}$, adapted to the Cobas Bio analyser. Int. J. Vit. Nutr. Res. 1990; 60: 126-35.

13 Powers HJ, Bates CJ, Prentice AM, Lamb WH, Jepson M, Bowman $\mathrm{H}$. The relative effectiveness of iron and iron with riboflavin in correcting a microcytic anaemia in men and children in rural Gambia. Hum. Nutr. Clin. Nutr. 1983; 37C: 413-25.

14 Calvin J, Neale G, Fotherby KJ, Price CP. The relative merits of acute phase proteins in the recognition of inflammatory conditions. Ann. Clin. Biochem. 1988; 25: 60-6.

15 Bates CJ, Prentice AM, Paul AA. Seasonal variations in vitamin A, C, riboflavin and folate intakes and status of pregnant and lactating women in a rural Gambian community: some possible implications. Eur. J. Clin. Nutr. 1994; 48: 660-8.

16 Bates CJ. Human riboflavin requirements, and metabolic consequences of deficiency in man and animals. Wld. Rev. Nutr. Dietet. 1987; 50: 215-65.

17 Smith FR, Goodman DS. The effects of diseases of the liver, thyroid and kidneys on the transport of vitamin A in human plasma. J. Clin. Invest. 1971; 50: 2426-36.

18 Yatzides H, Digenis P, Fountas P. Hypervitaminosis A accompanying advanced chronic renal failure. $\mathrm{Br} . \mathrm{Med} . J$ 1975; 3: 352-3.

19 Yatzides H, Digenis P, Koutsicos D. Hypervitaminosis A in chronic renal failure after transplantation. Br. Med.J. 1976; 2: 1075.

20 Farrington K, Miller P, Varghese Z, Baillod RA, Moorhead JF Vitamin A toxicity and hypercalcaemia in chronic renal failure. Br. Med.J. 1981; 282: 1999-2002.

21 Gentile MG, Fallin G, Manna GM, D'Amico G, Testolin G, Porrini M, Siminotti P. Vitamin A and retinol binding protein in chronic renal insufficiency. Int. J. Artific. Org. 1988; 11: 403-4.

22 Vannucchi MTI, Vannucchi H, Humphreys M. Serum levels of vitamin $\mathrm{A}$ and retinol binding protein in chronic renal patients treated by continuous ambulatorial peritoneal dialysis. Int. J. Vit. Nutr. Res. 1990; 62: 107-12.

23 Gal I, Parkinson C, Craft I. Effects of oral contraceptives on human plasma vitamin A levels. Br. Med.J. 1971; 2: 436-8.

24 Comstock GW, Menkes MS, Schober SE, Vuilleumier JP, Helsing KJ. Serum levels of retinol, beta-carotene and alphatocopherol in older adults. Am. J. Epidemiol. 1987; 127: 114-23.

25 Nierenberg DW, Stukel TA, Baron JA, Dain BJ, Greenberg ER and the Skin Cancer Prevention study group. Determinants of plasma levels of beta-carotene and retinol. Am. J. Epidemiol. 1989; 130: 511-21.

26 Herbeth B, Chavance M, Musse N, Mejean L, Vernhes G. Dietary intake and other determinants of blood vitamins in an elderly population. Eur. J. Clin. Nutr. 1989; 43: 175-86.

27 Muggeo M, Zenti MG, Travia D, Sartori A, Trimeloni S, Grigolini L, Graziani MS, Cigolini M. Serum retinol levels throughout 2 years of cholesterol-lowering therapy. Metabolism 1995; 44: 398-403. 